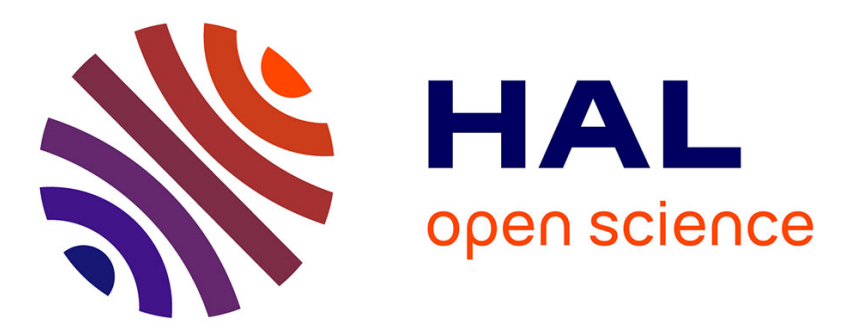

\title{
Influence of welding passes on grain orientation - The example of a multi-pass V-weld
}

\author{
Jing Ye, Joseph Moysan, Sung-Jin Song, Hak-Joon Kim, Bertrand \\ Chassignole, Cécile Gueudré, Olivier Dupond
}

\section{- To cite this version:}

Jing Ye, Joseph Moysan, Sung-Jin Song, Hak-Joon Kim, Bertrand Chassignole, et al.. Influence of welding passes on grain orientation - The example of a multi-pass V-weld. International Journal of Pressure Vessels and Piping, 2012, 93-94, pp.17-21. 10.1016/j.ijpvp.2012.02.007 . hal-00691194

\section{HAL Id: hal-00691194 \\ https://hal.science/hal-00691194}

Submitted on 25 Apr 2012

HAL is a multi-disciplinary open access archive for the deposit and dissemination of scientific research documents, whether they are published or not. The documents may come from teaching and research institutions in France or abroad, or from public or private research centers.
L'archive ouverte pluridisciplinaire HAL, est destinée au dépôt et à la diffusion de documents scientifiques de niveau recherche, publiés ou non, émanant des établissements d'enseignement et de recherche français ou étrangers, des laboratoires publics ou privés. 


\section{Influence of welding passes on grain orientation - \\ the example of a multi-pass $V$-weld.}

Jing YE.*, Joseph MOYSAN **, Sung-Jin SONG*, Hak-Joon KIM*, Bertrand

CHASSIGNOLE***, Cécile GUEUDRE**, Olivier DUPOND***,

* School of Mechanical Engineering, Sungkyunkwan University, 300

Chunchun-dong, Jangan-gu 440-746, Korea,Tel: +82-31-290-7493

**Laboratoire de Mécanique et d'Acoustique, site du LCND, Aix

Marseille-Université, Av. Gaston Berger, 13625 Aix en Provence, France,Tel: +33(0)4 42

939052

*** Département MMC, EDF R\&D, Site des Renardières, 77818 Moret-sur-Loing,

France, Tel: $+33(0) 160736309$

Jing YE: yejing@skku.edu

Hak-Joon Kim: hjkim21c@skku.edu

Sung-Jin Song: sjsong@skku.edu

Joseph Moysan: joseph.moysan@univ-amu.fr (corresponding author)

Bertrand Chassignole : bertrand.chassignole@edf.fr

Cécile Gueudré: cecile.gueudre@univ-amu.fr

Olivier Dupond : olivier.dupond@edf.fr 


\begin{abstract}
The accurate modelling of grain orientations in a weld is important, when accurate ultrasonic test predictions of a welded assembly are needed. To achieve this objective, Electricité de France (EDF) and the Laboratoire de Caractérisation Non Destructive (LCND) have developed a dedicated code, which makes use of information recorded in the welding procedure. Among the welding parameters recorded, although the order in which the welding passes are made is of primary importance in the welding process, this information is not always well known or accurately described. In the present paper we analyze in greater detail the influence of the order of welding passes, using data obtained from the Centre for Advanced Non Destructive Evaluation (CANDE), derived from a dissimilar metal weld (DMW) with buttering. Comparisons are made using grain orientation measurements on a macrograph.
\end{abstract}

ultrasound

Keywords: austenitic weld, grain modelling, influence of welding pass order,

\title{
1. Introduction
}

Austenitic stainless steels are widely used in the nuclear industry due to their high corrosive resistance and excellent creep properties over a wide range of temperatures. The inspection of austenitic material welds using classical focused transducers or phased array transducers may be difficult, because the grain orientation induces ultrasonic beam deviations and splitting. As a consequence, an accurate description of the material is a necessary precondition for reliable results to be obtained in ultrasonic modelling and testing. 
Several material models use geometrical laws, derived from the analysis of macrographs [1-8], to describe grain orientation. Over a period of several years, a more complete approach to the modelling of grain orientation has been developed by EDF and LCND. This has been encoded into a software package referred to as 'MINA', which makes use of information recorded in the welding notebook, the modelling of solidification mechanisms, and parameters extracted from the weld macrographs $[9,13]$. The validation of MINA has been presented in several papers [10,11]. The welding pass order was considered to be a known parameter in previous studies of academic welds. Four main phenomenological parameters, chosen on the basis of prior experience, are needed to run the MINA code: firstly, the vertical and lateral remelting parameters allow the remelting of passes to be described, and secondly, the two angles describing the pass inclination are needed [10]. However, in real welds, due to the difficulties associated with manual welding, other parameters could also modify the passes deposition process. Various modifications could occur, without been reported in the welding notebook, since the welder may adapt the pass order to the variations inherent in the welding process, such as the deposition rate and grinding procedures between passes. A slight inclination of the pass layer could lead to two different descriptions of the pass order, as shown in the example of the weld specimen (white arrow) in Fig. 1.

In the present paper, we investigate the feasibility of using the MINA model to overcome this difficulty, and the degree of sensitivity of the modelling process.

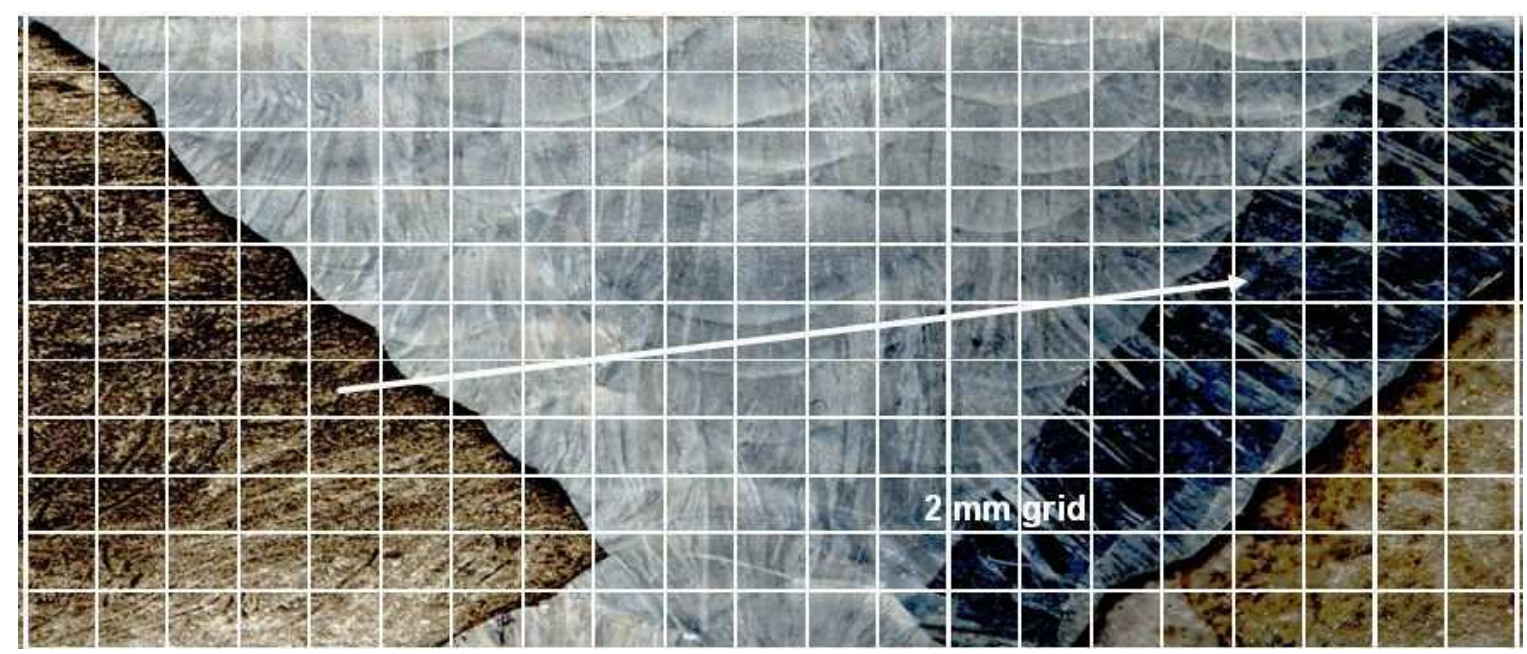

Figure 1: Macrograph of a real specimen, with buttering 
and a grid overlay for grain orientation measurements.

We compare the two most realistic welding pass orders, and their influence on grain orientation. The grain orientations predicted by our model are compared with those simulated by the Modified Ogilvy model [14], and with those measured on the welding samples. In [14], Ye Jing et al. describe an optimization algorithm used to fit Ogilvy's parameters to our weld specimen. The novelty of this approach lies in their use of two sets of parameters, in order to take asymmetrical orientation distributions into account.

The MINA parameters are firstly evaluated using macrograph analysis, then we explain how order of passes could be modelled. In a third step we compare modelling results (local grain orientations) with macrograph measurements.

\section{Evaluation of MINA parameters}

Three physical phenomena are involved in the MINA model: epitaxial growth, the influence of temperature gradient, and competition between grains. Epitaxial growth implies that, at every point, the melt metal adopts the crystallographic orientation of the underlying pass. The grain direction could change during growth, but the crystallographic orientation would be maintained. Grains have a propensity to align themselves in the direction of the temperature gradient. In the case of multi-pass welding, there are local temperature gradient direction changes due simply to the shape of the welding pool. There is competition between grains, as they grow preferentially if one of the $\langle 100\rangle$ crystallographic axes is aligned close to the direction of the temperature gradient. The MINA model takes this competition into account, using a specific iterative calculation, which depends on the modelling scale [10].

In order to take overlapping of passes into account, two input parameters, determined by analyzing the weld macrograph, are used in MINA: $\mathrm{R}_{\mathrm{L}}$ and $\mathrm{R}_{\mathrm{V}}$, which represent the lateral and vertical remelting rates of the current pass, respectively [10]. Following the parameter used to describe the welding pass order, these two parameters are the most important. Average values could also been obtained from other welds, using a 
similar welding process. From measurements of the weld made at CANDE, the average values of $\mathrm{R}_{\mathrm{L}}$ and $\mathrm{R}_{\mathrm{V}}$ are respectively 0.29 and 0.44 , which is in agreement with previous studies using the SMAW process [10].

The observation of the macrograph of a multipass weld shows that the passes have a parabolic shape and are tilted. Two other MINA parameters are used: $\theta_{\mathrm{B}}$ describes the angle of inclination of the pass towards the edge of the chamfer, and $\theta_{\mathrm{C}}$ describes the angle of inclination of a given pass with respect to the previous pass. In the MINA code, this phenomenon is taken into account by rotating the direction of the temperature gradient, with no change in the geometric shape of the pass. The average value of $\theta_{\mathrm{B}}$ is $12^{\circ}$, and the average value of $\theta_{\mathrm{C}}$ is $7^{\circ}$. These are average values, obtained from approximately ten to twenty measurements, from a total of thirty-three passes. There is no tilt angle when the pass is deposited between the chamfer and a previous pass, or between two previous passes. The MINA code produces a matrix of grain orientation. The matrix size depends on the chosen scale and on the chamfer dimensions.

\section{Pass order analysis}

The dissimilar metal weld (DMW) specimen under investigation (figure 2) has a V-shaped chamfer filled with 33 weld passes by using the filler material made of EniCr-Fe-3 (Alloy 182). The welding process of Groove is Shielded metal arc welding (SMAW), and the welding position is flat position. The welded zone is $22.7 \mathrm{~mm}$ thick, the top width is $40 \mathrm{~mm}$ and the weld root is $2 \mathrm{~mm}$. The base material of one side of the weld is SA508 Gr.3, which is a kind of mild steel; the base material of the other side of the weld is SA240 tp304. This weld also embodies a buttering part in between the weld (austenitic steel) and mild steel. The buttering by Gas Tungsten-Arc Welding (GTAW) is made of is ERNiCr-3 (Alloy 82) (Inconel 600). Like some of the works on DMW, the material property along the axis normal to the inspection plane is assumed to be homogeneous, for along this axis there's only one pass during welding [9]. Except the SA508 Gr.3,

EniCr-Fe-3, ERNiCr-3 and SA508 Gr.3 share the same elastic constants of material property as austenitic stainless steel. The sound velocities of mild steel are $C_{L}=5900 \mathrm{~ms}^{-1}$ 
and $\mathrm{C}_{\mathrm{T}}=3196 \mathrm{~m} \cdot \mathrm{s}^{-1}$. The elastic constants of the transversely isotropic austenitic stainless steel are $\mathrm{c}_{11}=241.1 \mathrm{GPa}, \mathrm{c}_{12}=96.916 \mathrm{GPa}, \mathrm{c}_{13}=138.03 \mathrm{GPa}, \mathrm{c}_{33}=240.12 \mathrm{GPa}, \mathrm{c}_{44}$

$=112.29 \mathrm{GPa}$, and the mass density is $7890 \mathrm{~kg} \cdot \mathrm{m}^{-3}$. The multipass weld was composed of 33 runs.

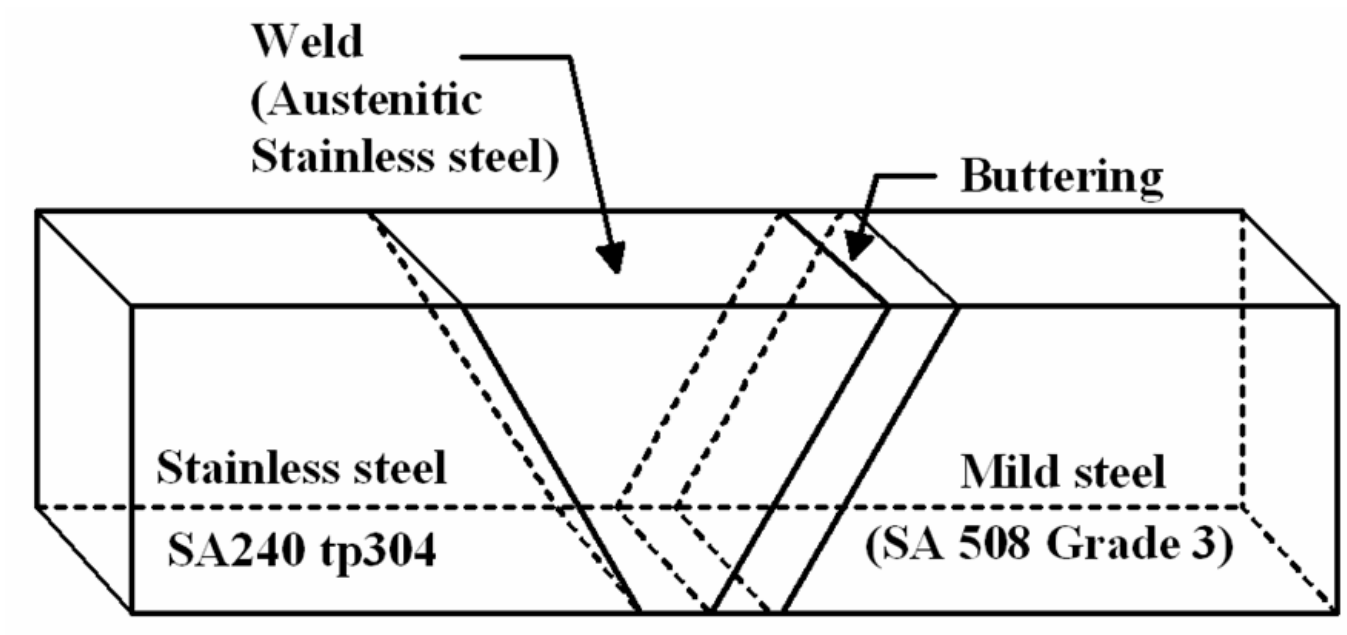

Fig.2 Description of the Dissimilar Metal Weld

The electrode diameter was $4 \mathrm{~mm}$ for all the passes, and the welding speed varied between 13 and $16 \mathrm{~cm} / \mathrm{min}$ for the first pass, and 15 and $19 \mathrm{~cm} / \mathrm{min}$ for the following passes. The inter-pass temperature varied between $30^{\circ} \mathrm{C}$ and $110^{\circ} \mathrm{C}$. From the macrographs (Fig.1), it can be seen that the pass shape is parabolic, which is in agreement with the assumptions made in MINA. Both the remelting parameters and the electrode tilt angles could be considered to be virtually constant. It is also reasonable to consider the grains to be tilted only in the plane transverse to the welding direction, since the grains appear clearly on a transverse macrograph. This confirms that there are no significant 3D effects modifying grain growth, when the welding procedure is made in a flat position. The welding procedures and macrograph thus comply with the hypotheses used in the MINA code [10].

In addition, the CANDE welding notebook indicates the number of layers and the number of passes used for each of the 10 layers. In the flat welding position, there are three possible classical welding sequences. The first of these is referred to as being parallel when the passes are deposited for each pass, from left-to-right or right-to-left. The second 
sequence involves the use of 'alternate' passes (left-to-right then right-to-left), and the third possibility is that of the 'American' sequence, involving the side to side deposition of passes (see the pass order shown in Fig. 3). In Fig. 3 the shape of the passes is shown qualitatively, in order to indicate the pass position. The notebook indicates that the weld was deposited from right to left, with the exception of the $8^{\text {th }}$ layer, which was welded from left-to-right. This pass order is referred to as 'Solution 1' in Fig. 3.

During a manual welding process, variations may arise. In the case of the weld described here, after careful examination of the macrograph, two observations can be made. The macrograph analysis reveals that, due to the slight slope of the passes, these are not aligned horizontally. Secondly, the change in pass order at the $8^{\text {th }}$ layer means that the $18^{\text {th }}$ pass could be considered to be a pass of the $7^{\text {th }}$ or the $8^{\text {th }}$ layer. The pass order can thus be simulated using two different descriptions: Solution 1, which is closer to the notebook, and Solution 2 which takes the second approach to interpretation of the "slope" induced by manual welding into account.

Three orders of passes (or passes sequences) are considered in the MINA model to reproduce real welding conditions. Two of them are classical order of passes : continuous sequence from one side to the other, beginning on the right side or on the left side. The third one, called the american way in previous works $[10,13]$, refers to an alternate pass deposit. A pass is deposited on one side, the next is then deposited on the opposite side. In this welding procedure, the final pass of the layer is in the centre of the weld and not on one of the two sides. In Fig. 3, the symbol "US" at the beginning of the pass order for each layer indicates the use of the "american" welding technique, where L indicates Right-to-Left and R indicates Left-to-Right. The grain orientations predicted for these two solutions are compared with reference grain orientation measurements, made using image processing software used in previous studies [10,11]. 


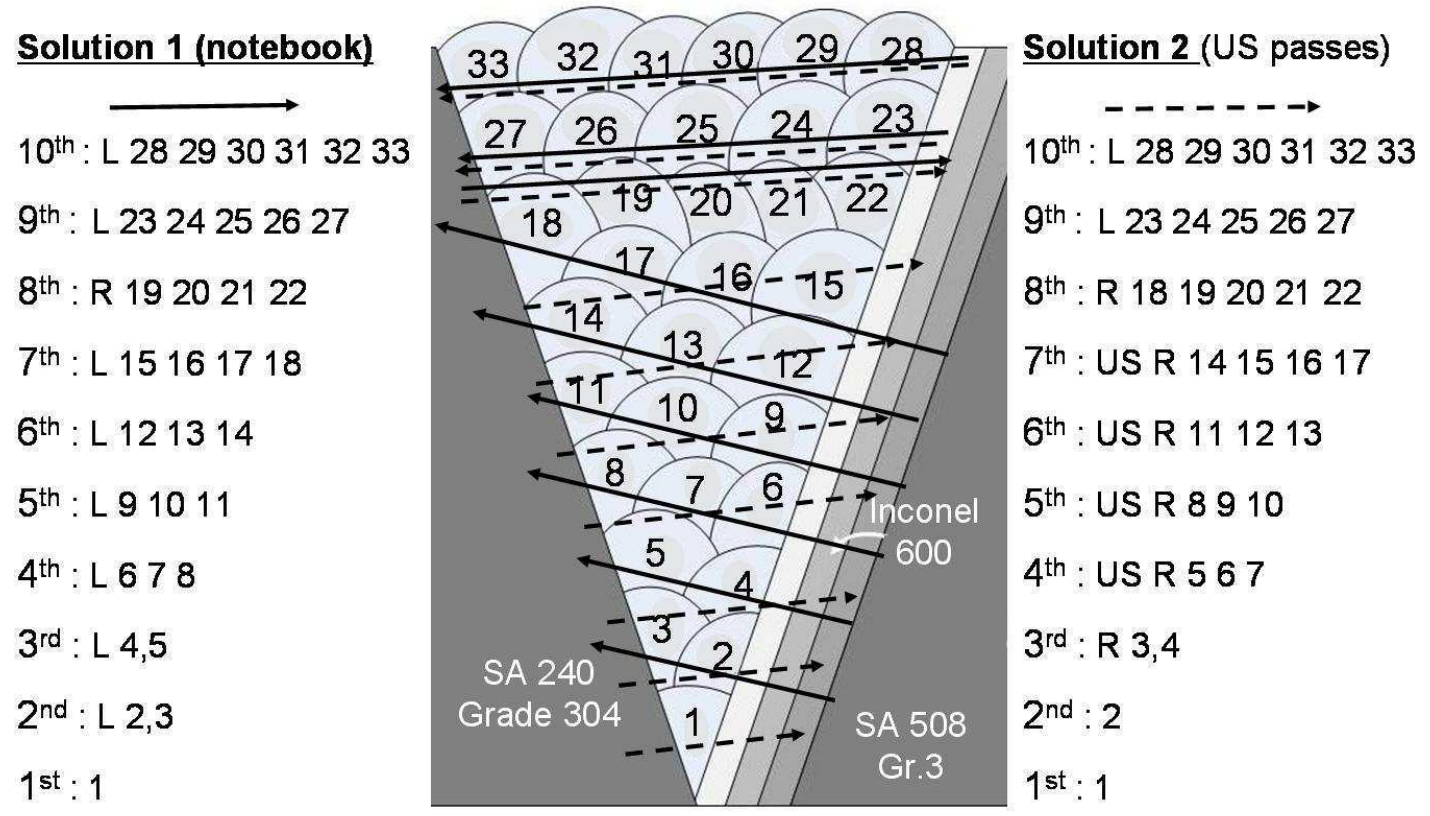

Pass order: L: left-to-right; R: right-to-left , US: "american way" Fig.3 Materials, weld configuration and two solutions for welding pass order

\section{Comparison between grain orientation simulations}

\section{and measurements and discussion.}

In this section the grain orientations calculated by modelling are compared to reference measurements made by EDF using optical measurements on macrographs. The scale used for this analysis is $2 \times 2 \mathrm{~mm}$, since it has previously been shown that this allows a good compromise to be found between accurate ultrasound modelling and data volume, when the conventional frequencies of 1 or $2 \mathrm{MHz}$ are used for the ultrasonic testing. The wavelength corresponds to a few millimeters, whereas the grain size is approximately 200 $\mu \mathrm{m}$ [9]. The chamfer widths used in the model were $40 \mathrm{~mm}$ at the upper part of the weld, and $4 \mathrm{~mm}$ at the bottom, with an overall height of $24 \mathrm{~mm}$. The final grain orientation matrices have dimension of 40x20 mm, as the weld is planned (see Fig. 1). The grain orientations varied from 0 to $180^{\circ}\left(90^{\circ}=\right.$ vertical orientation $)$. MINA resulting grain orientation matrix is calculated with the same $2 \times 2 \mathrm{~mm}$ scale. This procedure enables to have the same matrix dimensions for the comparison. The difference matrix between the reference measurements and the modelling results is simply the difference of the two 
corresponding matrices. When the modelling value corresponds to the reference value the difference is zero. Large differences could be locally observed ( $30^{\circ}$ or more). This difference matrix is converted as a map of differences in figure 2 . The use of level lines and grey colour scale enable a global analysis of MINA modelling results. These maps make easier various parametric studies.

Several conclusions can be drawn from these figures. Firstly, the mean error $\left(\Delta_{\theta}\right)$ and the standard deviation $\left(\sigma_{\theta}\right)$ between the reference and model values lie globally in the same domain, i.e. between $15^{\circ}$ and $17^{\circ}$ for the mean value, and approximately $10^{\circ}$ and $12^{\circ}$ for the standard deviation. In a previous study of more academic welds, the value for $\Delta_{\theta}$ mean ranged between approximately $10^{\circ}$ and $13^{\circ}$ [10]. As this weld is more complex, and due to the slight slope of the layers, these values reflect more variations between modelling and macrograph measurements than in the previous study. The final error maps show that the MINA model is not excessively sensitive to this slight slope, despite the fact that it is not reproduced in the modelled approach.

Secondly, the error maps ((a) and (b)) demonstrate that the welding pass order recorded in the notebook leads to the best solution, even though the alternative solution (Solution 2) is not very different from Solution 1. The grain orientation difference between Solutions 1 and 2 has an average value of $8^{\circ}$. Local grain orientation differences could be expected to produce some modifications to the predicted ultrasound beam behaviour. Thirdly, in order to degrade the results, substantially incorrect notebook recordings are needed. For example, Solution 3 used in Fig. 4 (d) is composed of 8 layers (number of passes per layer: 1, 2, 2, 3, 3, 3, 4, 4), using a Left-to-Right pass order. This confirms that the MINA model is robust.

Fourthly, our comparison with the analytical solution given by Ogilvy's model, adapted to the CANDE weld, shows that the MINA model is closer to the reference solution even though the asymmetrical behavior was taken into account in the analytical solution [14]. In the case of the CANDE weld, the difference between the two models is smaller when the mean value is considered. Nevertheless, due to a large area towards the left side of the weld in which there is a change in the resulting orientations, differences in 
ultrasound propagation could be expected. It is also interesting to note that the buttering has little effect on grain growth, as there are no strong differences near to this zone. It was observed that the grains in the buttering zone are quite perpendicular to the chamfer, and this observation is in agreement with the assumptions made in the MINA code [4].

Fifthly, the errors are always localised in the same area (left and upper left zones), which is most probably a consequence of the modification to the welding process during the $18^{\text {th }}$ pass as the order of passes is changed : from right to left it changes to left to right. This $18^{\text {th }}$ pass probably remelted at the outside edge of the layer, producing an unusually large deposit. Such a variation in the deposits made during passes should be avoided, to avoid any change to the symmetry of the process, which would have a noticeable effect on grain orientations. No model is able to take into account such phenomena at this moment. It confirms the need of a careful record of the welding procedure by the welder for a better understanding of the weld properties. For the sole ultrasonic point of view it is known that if a large area is characterised by a difference in mean grain orientation, the beam path is modified [11].

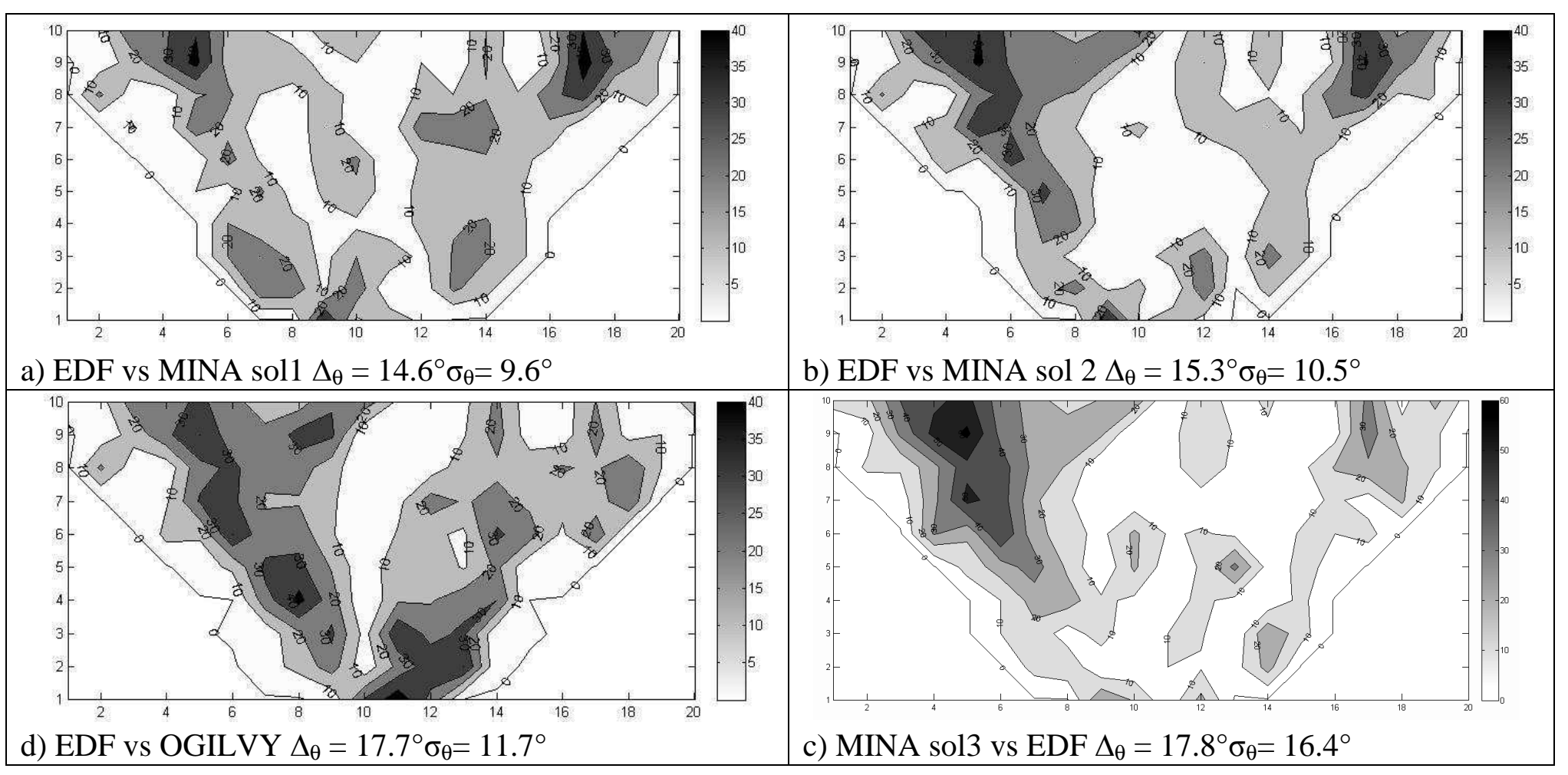

Fig.4. Contour plots of grain orientation differences. 


\section{Conclusions}

In this paper, we focus on the grain orientation description of a bimetallic austenitic stainless steel weld. The MINA code was used to simulate the grain orientation of a multi-pass weld, and for the analysis of a macrograph of the weld.

We show that even a macrograph may be read in two different ways; overall, the grain orientation could be correctly predicted with a better accuracy than an analytical solution. Nevertheless, it is also clear that the correct pass order is highly crucial to grain growth, such that, together with a correct description of the number of passes in a layer, it is the most important parameter in describing a weld.

A generic solution would be to use the advanced modelling tool (MINA) in an inverse process, to reconstruct unknown parameters. Good results were obtained by C. Gueudré et al. with remelting parameters [13]. The latter study demonstrated that the most crucial point is that of reconstructing the pass order using the inverse technique, whenever the welding notebook is unreliable. However, it should be pointed out that, from the mathematical point of view, the inverse problem is more complex [15]. The pass sequence also influences residual stresses [16-17]. It would be of great interest to combine these two research fields to propose the best sequence order : improving ultrasonic investigation and reducing residual stresses.

The MINA code has been dedicated to shielded metal arc welding and flat welding. Some preliminary works have been done to enlarge the applications to TIG welding and welding in position [12]. This would be developed in the framework of a French collaborative research programs called MOSAICS at the beginning of 2012.

More recently, ultrasonic phased array testing has been increasingly adopted for the inspection of dissimilar metal welds, since this technique can improve the probability of detections (PODs), and has an improved sensitivity to defects located in attenuating 
media and specimens with complex curvatures. In the case of phased array transducers, the delay laws could be incorrectly calculated with incorrect material descriptions [14]. The advantage of the MINA model is confirmed when it is vital to achieve more realistic grain orientation predictions.

\section{Acknowledgements}

We gratefully acknowledge the support provided by the LCND, and CANDE, and SKKU. The authors also wish to thank EDF R\&D in Moret sur Loing (France) for granting them with permission to use the MINA code for this study, and thank KINS for its support with DMW research.

\section{References}

[1] M.G. Silk, A computer model for ultrasonic propagation in complex orthotropic structures, Ultrasonics,1981 , $19: 208-212$.

[2] J.A. Ogilvy, Computerized ultrasonic ray tracing in austenitic steel, NDT\&E International, 1985, $18: 67-77$

[3] Harker HA, Ogilvy JA. Coherent wave propagation in inhomogeneous materials: a comparison of theoretical models. Ultrasonics 1991;29:235-44.

[4] V. Schmitz, F. Walte, S.V. Chakhlov, 3D ray tracing in austenite materials, NDT\&E International, 1999, $32:$ 201-213.

[5] M. Spies, M. Kroning, Ultrasonic inspection of inhomogeneous welds simulated by a gaussian beam superposition, Review of progress in Quantitative Nondestructive Evaluation, Vol. 18, Plenum Press, 1999, p 1107-1113

[6] S. Halkjaer, M.P. Sorensen, W.D. Kristensen, The propagation of ultrasound in a austenitic weld, Ultrasonics, 2000, $38: 256-261$

[7] K.J. Langenberg, R. Hannemann, T. Kaczorowski, R. Marklein, B. Koehler, C. Schurig, F. Walte, Application of modeling techniques for ultrasonic austenitic weld inspection, NDT\&E International, 2000, 33 : 465-480.

[8] Q. Liu, Wirdelius H., A 2D model of ultrasonic wave propagation in an anisotropic weld., NDT\&E International, 2007, $40: 229-238$

[9] Chassignole B, Villard D, Dubuguet M, Baboux JC, El Guerjouna R. Characterization of austenitic stainless steel welds for ultrasonic NDT. Rev Prog QNDE 2000;20:1325-32.

[10] Moysan J., Apfel A., Corneloup G, Chassignole B, . Modelling the grain orientation of austenitic stainless steel multipass welds to improve ultrasonic assessment of structural integrity. Int J Pressure Vessels Piping 2003;80:77-85. 
[11] Apfel A., Moysan J., Corneloup G., Fouquet T., Chassignole B., , Coupling an ultrasonic propagation code with a model of the heterogeneity of multipass welds to simulate the ultrasonic testing. Ultrasonics 2005; 43: 447-456

[12] Moysan J., Gueudré C., Ploix M.A., Corneloup G., Guy P., El Guerjouma R., Chassignole B., Advances in Ultrasonic Testing of Austenitic Stainless Steel Welds. Towards a 3D Description of the Material Including Attenuation and Optimisation by Inversion, in Ultrasonic Wave Propagation in Non Homogeneous Media, Editors A. Leger, M . Deschamps, in Ultrasonic Wave Propagation in Non Homogeneous Media, Series: Springer Proceedings in Physics, 2009; $128: 15-24$

[13] Cécile Gueudré, Loïc Le Marrec, Joseph Moysan, Bertrand Chassignole. Direct model optimisation for data inversion. Application to ultrasonic characterisation of heterogeneous welds. NDT\&E International 2008;42:47-55.

[14] Jing YE, Sung-Jin Song, Hak-Joon Kim, Sung-Sik Kang, Kyungcho Kim, Myung-Ho Song, Model-based simulation of focused beam fields produced by a phased array ultrasonic transducer in dissimilar metal welds, NDT\&E International 44 (2011) 290-296

[15] C. Gueudre, M. Checkroun, J. Moysan, G. Corneloup, Search of the Order of Passes of an Austenitic Weld by Optimization of an Inversion Process of Ultrasound Data, Review of Progress in Quantitative NDE, San Diego, USA, July 18 - 23, 2010

[16] H.J. Yi; J.Y. Kim, J.H. Yoon, S.S. Kang, Investigations on welding residual stress and distortion in a cylinder assembly by means of a 3D finite element method and experiments, Journal of Mechanical Science and Ttechnology, 25 (2011) 3185-3193

[17] D. Rudland, A. Csontos, T. Zhang, G. Wilkowski, Welding Residual Stress Solutions for Dissimilar Metal Surge Line Nozzle Welds, Journal of Pressure Vessel Technology-Transactions of the ASME, 132 (2010) 353-359 